\title{
Fabricated Expertise: A Risk to Educator Freedom
}

\author{
Brett J. Holt \\ University of Vermont, USA
}

\begin{abstract}
What determines expertise? What is an "expert" educator? What are the credentials an "expert" should possess? The discourses and dispositions of Ericsson, Berliner, Marion, and Firestein will help determine answers to these questions creating a foundation in which to view expert educators. Attention is given to accepted expert considerations for both academic and grade school educators (i.e. Preparatory Training, Government Licensure, Years of Service, Visibility, Professional Maintenance, Promotion, etc.). After identifying educator expertise, the author will examine various ways in which false expertise is enabled including but not limited to: Lack of accountability, emergency need, loyalties without consideration, profiteering, reference neglect, attribution, dispositional conformity, and false assumptions. Identification characteristics are provided for recognizing genuine and false experts. By taking a look at common practices used by school/college administrators, elected officials, organizations, and other non-professionals that have inadvertently or possibly willfully enabled false expertise of educators, the author will conclude that the educational academies might begin to recognize the dangers posed to educator freedoms (i.e., Argumentum ad Veracundiam, loss of public trust, and credibility). If educators are unable to defend this assault on educator freedoms (defined within the scope of Lehrfreheit and Lehrnfreheit) enabled by false expertise, the author determines that society will lose faith in education.
\end{abstract}

\section{Introduction}

The only true wisdom is knowing that you know nothing - Socrates

This paper will first operationalize "expertise" through the presentation of dominant philosophical discourses. Next, the paper will seek to identify common expert considerations for both the grade school educator and the academic educator. After both discussion and examples are presented on how false expertise is enabled in the education discipline, the author will question potential negative effects of enabling false expertise. Finally, the author intends to leave the reader with a philosophical disposition that questions the damage potentially being done to the education profession.

\section{What is an Expert?}

In order to determine what constitutes an "expert," the author will first identify common dominant philosophical discourses on the topic of expertise.

Ericsson [1, 2, 3] has studied multiple disciplines (Teachers, Photographers, Radiologists, Olympic Figure Skaters, Wine Tasters, etc.) in order to answer, "what is an expert?" Ericsson found that all experts in had one thing in common: 10,000 (+) hours of engagement in their respected field. When one thinks about the average full-time work week as 40 hours per week, this comes to approximately five full years of engagement at full-time work or ten years of engagement at part-time work (20-hour work week). Interestingly, Ericsson suggests that only approximately two to four hours daily of sustained concentration and practice is possible, thus hinting more toward the tenyear part time engagement.

While discussing some of the criticism on Ericsson's work in regards to conflating "best" performance with that of "expert" performance, Lebowitz [4] contends that the base characteristic of "expertise" remains (even from the "best performers") at a minimum of 10,000 (+) hours of engagement time. For instance, critics might be tempted to point to Tiger Woods (as the youngest Master's golf tournament winner; '97) as evidence that the 10,000 (+) engagement hours could not possibly be accurate since his "best" performance was achieved earlier than the "best" performance of his competitors. However, the critics would be ignoring the fact that Woods had, indeed, accumulated in his young golf career the minimal 10,000 (+) engagement hours that characterizes an expert. 
While just 10,000 (+) hours of engagement is the common theme and the basis for Ericsson's work, Ericsson also regards "Deliberate Practice" as an important component to developing expertise [3]. Deliberate practice means that one engages in 10,000 $(+)$ hours and is willing to engage in new and novel forms of practicing that enhances a skillset. Ericsson provides the example of the world class chess player who in order to develop expertise cannot just engage in $10,000(+)$ hours of chess playing, but will also need to engage in 10,000 (+) hours "deliberately" designed to allow the chess player to assess and revise his/her skillset.

In the education discipline, we similarly have adopted a learning disposition of providing students with "Allocated Learning Time [5]." Providing Allocated Learning Time (ALT) for our students highlights education's commitment to developing expertise in various subjects. In fact, similar to "Deliberate Practice," ALT has been known to be referred to as "appropriate" or "inappropriate," depending on the success rate/s of the student/s.

Berliner [5, 6] expands on the notion of expertise by claiming that expert educators had developed "automaticity" of their processes [6]. For example, many of us now "walk" without much thought other than direction. However, none of us were born walking and had to learn the skill. Therefore, Berliner would, likely, conclude that majority have become "experts" at walking due to the fact that it has become an "automatic" process for most. Berliner [5] describes expert educators as having developed critical skills not just in teaching strategies but also in classroom management strategies.

World renowned poet, T. S. Eliot, has been credited with suggesting that the quality of a scholar's ignorance is what distinguishes the expert [7]. The argument is being made that experts often have a higher quality of ignorance concerning areas where their expertise may be lacking; Or, that our ignorance on particular subjects is not at the same level of incorrectness. Likewise, Firestein would maintain that ignorance is needed for hypothesis testing [8]. In order to determine quality of ignorance, Firestein, fascinatingly, invited recognized experts in various disciplines to speak on topics in which they do not have expertise. By asking identified experts in their respected field to speak on topics that they are not familiar, Firestein [8] attempts to measure what Eliot [7] refers to as quality of ignorance.

Likewise, Theologian, Academic, and Philosopher Marion [9] when discussing the "expertise paradox" points out to college students that they will only take approximately 32 courses at a university that offered more than 8,000 courses. The Expertise Paradox, as asserted by Marion [9], claims that the immensity of what one does not know is greater than what one does know. And, that the more we learn, the more we are aware of what we do not know. Further, Marion [9] suggests that we will eventually reach a point where society transforms us into subjects that are supposed to know without the benefit or the freedom of inquiring or pursuing what it is that we do not know, thus the paradox.

As one can envision, there exist multiple scholarly discourses governing the identification of an expert. In the following section, this author intends to focus on common expert considerations given to both academic educators and grade school educators.

\section{Expert Considerations for Educators.}

Both academic and grade school educators have determined common minimal criteria for being considered an expert. The author has provided a table and discussion to summarize the expert considerations given to both academic and grade school educators.

Table 1. Considerations for educator expertise

\begin{tabular}{|l|l|}
\hline Grade School Educators & Academic Educators \\
\hline $\begin{array}{l}\text { Preparatory studies } \\
\text { (Recognized) }\end{array}$ & Terminal degree in field \\
\hline Degree related to field & Tenure/promotion \\
\hline Licensure & Visibility of work \\
\hline $\begin{array}{l}\text { In-service/Professional } \\
\text { Development participation }\end{array}$ & Juried work \\
\hline Years of service & Service to the field \\
\hline
\end{tabular}

\subsection{Grade School Considerations.}

In grade school education, consideration is given to several factors when determining expertise. One such consideration is the college degree that the grade school educator has achieved. Specifically, is the degree related to the field in which they have been assigned to teach/practice? For example, has the grade school Mathematics teacher accomplished degree studies in Mathematics, or did the Math teacher study something else entirely (i.e., Art) while in college and has been asked to teach grade school mathematics?

Secondly, is the degree earned by the grade school educator backed by a recognized accreditation agency that would provide oversight on the curriculum? Both credible institutions and programs are willing to undergo accreditation review. The accreditation agencies typically consist of previously identified experts that review either the institution or the program curricula. Many of those accrediting agencies, themselves, are often subject to review by government agencies (e.g., the National Advisory Committee for Institute Quality and Integrity: A congressional committee in the United States that provides oversight of the accrediting agencies). This curricular oversight is a form of experts monitoring development in any particular academy including the education academies. 
One of the most common criteria associated with an expert grade school teacher is thought to be a (teaching) license. A teaching license, similar to a driver's license, is usually conferred by a government agency (Federal, State/Provincial, Local, etc.). In other words, a grade school teacher that has accomplished the minimal criteria (i.e., cut score for particular exam) as determined by a government agency will receive the endorsement or approval of said government agency within their district.

Years of service in the education profession is assumed to be another consideration of expertise in grade school educators. Many school systems reward years of service by offering financial incentives on a career ladder. For instance, a grade school teacher in his/her third year of teaching might make less monies than the teacher in his/her tenth year of teaching even though their teaching responsibilities might be the same (i.e., same amount of classroom children, same curricular topics, etc.). This draws a parallel with the afore mentioned characteristic of expertise [1, 2, 3] as defined by Ericsson (10,000+ engagement hours) and rewards grade school educators for accumulating more engagement time in the profession.

Finally, grade school educators who actively engage in professional development opportunities are often believed to be developing their expertise. In-service or Professional Development opportunities for grade school educators may include attending conference sessions, attending guest lectures, participating in community related activities (i.e., library book drives for the Literature teacher or Community Chorus for the Choral teacher), outreach activities (i.e., community swim lessons or recreation/playground construction for the Physical Education teacher), or even other external volunteerism/employment that is relatable (i.e., Religious/Summer Camp theatre for the Drama teacher or Daycare for the Elementary/Early Childhood school teacher). Each of these examples would add to the expertise being developed by the grade school educator.

While there may be further considerations in determining an expert grade school educator, the factors mentioned are commonly considered throughout the education discipline.

\subsection{Academic School Considerations}

Academic educators consider several criteria when identifying expertise of their faculty. Perhaps, the most common characteristic considered for an expert academic educator is the earning of a terminal degree (Ph.D., Ed.D., M.D., J.D., D.D.S., D.F.A, etc.) in one's discipline. As such, the general public will often attribute expertise to individuals who have earned a doctoral degree in a particular field. For example, a person may witness news agencies interviewing or judicial hearings inviting testimony from individuals who hold a doctoral degree in a selected field of study as recognized experts in a particular discipline.

One of the most universally considered criteria for expert status in the academic education discipline is thought to be the tenure/promotion process in which the academic educator is subjected. It is common for fulltime academics have their academic credentials reviewed both internally and externally through the tenure process. Frequently, the tenure/promotion process at a college/university includes detailed review of the academic educator's scholarship endeavors, teaching/learning endeavors, and service endeavors. For example, the tenure/promotion process at this author's university includes an external review/vote by six "arm-length (less professional or personal association)" tenured faculty members in the identified discipline at sister institutions and an internal review that allows for all current tenured faculty within the housed department to review/vote. When considering scholarship, the reviewers are instructed to review type, quantity, and quality of scholarly endeavors. For teaching/learning endeavors the academic educator is reviewed on student evaluations, peer-faculty teaching evaluations, administrative evaluations, and supporting evidences such as syllabi, professional development sessions attended, etc. When reviewing service the candidates service to the department, college, university, community, and discipline are all contextually considered.

Visibility of one's work is another common criterion considered when determining the level of expertise for an academic educator. Visibility of one's work could include circulation rate of publications, impact factor of publications, and audience type of presentation/performance (international, national, regional, or local audience).

A common criterion for expertise in academic educators is considered when work has been juried. Juried work typically indicates that a group of already identified experts in a particular field has reviewed and approved the work that is being completed by the academic educator. For instance, more credibility might be given to the academic that publishes his/her scholarship in a juried journal rather than a non-juried magazine. Sometimes the juried work is reviewed blindly to eliminate biases, but not always. One of the most common expectations in the academic profession is to have your work juried for the reason of achieving the afore mentioned tenure/promotion process.

Sometimes, the amount of service, similar to grade school educators, to the field/discipline is considered when determining expertise in academic educators. For example, has the academic educator served the discipline/field of study by acting in the capacity of advancing knowledge in the field? Some common examples of academic educators serving the discipline/field of study would include acting in the 
capacity of the previously mentioned juried reviewer (i.e., journal review, conference review, tenure review, etc.), acting as an editor or part of an editorial board, engaging in outreach projects that help advance a part or the whole discipline (i.e., providing in-service training to grade school educators), etc.

While there may be further considerations in determining an expert academic educator, the considerations already mentioned are common considerations throughout the academic education discipline.

\section{Enabling False Expertise}

"Enabling" is loosely defined by the freedictionary.com as providing resources (in an abusive context) that help to escalate rather than resolve problems [10]. Enabling can happen when individuals provide resources (including motivation) that escalate a problem. Kaleghi [11] cautions against conflating "enabling" with "empowering." Unfortunately, some individuals will enable false expertise under the guise of "empowerment." However, this conflation of terms/concepts could endanger the credibility of the expert. The Dunning-Kruger effect helps one visualize enabling of false expertise. The Dunning-Kruger effect [12] describes how individuals often view their abilities and credentials with more confidence than what others would view their credentials. Kominsky [13] describes the potential hazard of the Dunning-Kruger effect by providing an example of two individuals asked, "how many leaves are on a tree?" While individual "A" may answer (incorrectly) with a high degree of confidence, individual "B" would answer with, "I do not know." In this scenario, individual " $\mathrm{B}$ " is demonstrating the least amount of ignorance because s/he is admitting to not knowing when the truth is that s/he does not know; However, the lay society is more apt to accept the answer from individual " $A$ " because even though $\mathrm{s} / \mathrm{he}$ answered incorrectly, they answered with more confidence, thus enabling of false expertise. False expertise can be enabled in individuals through both a) purposeful or b) accidental actions. The author has offered both purposeful and accidental examples and explanations enabling false expertise in education.

\subsection{Purposeful}

In education, we often times willfully ignore the criteria that we have previously set forth as a solution to a problem that we face. For example, many education administrators may ignore the criteria of an earned teaching license in lieu of filling a vacant position, if there are no other candidates and the education administrator feels that the desire to have a position filled outweigh the negative consequences on not committing to "expertise."
Another recurring example of purposeful enabling of false expertise occurs when education and academic employers sacrifice expertise for loyalty to a friend or family member. How often have employers hired friends or family without consideration of their expertise? Similarly, individuals may vote for elected positions that lack expertise but are friends and family of the voter. Some of these elected officials (e.g., school board members, superintendents, etc.) can have damaging decision-making authority on educators. Purposeful enabling of false expertise can further occur when social conformity is expected. Instead of hiring due to expertise, an education administrator, as another example, might hire due to a predetermined social disposition. This author speculates that many readers have heard the common saying (or similar) when being denied a job, "we are sorry to inform you that we hired another candidate because they were a better fit." This statement does not question the applicant's qualifications or expertise rather it seems to indicate that there was a predetermined social disposition that the other (possibly less qualified and less "expert") candidate demonstrated (i.e., this author is aware of academic hires that have had their hobbies considered by search committees).

One purposeful example of enabling false expertise (arguably, in every discipline) is the falsified résumé or curriculum vita $(\mathrm{CV})$. Some individuals have falsified information on their résumé/CV, including but not limited to: a) enhanced responsibilities, b) enhanced temporal commitments, c) fabricated degrees/majors/minors/etc., d) false or enhanced projects, e) false decision-making roles, and f) monetary embellishments, and are not held accountable for their fabricated CV. In particular, it should be cautioned that some online tools and websites designed to connect potential employers with candidates possessing expertise have a lack of accountability in what is being publically published online. One of the few ways to determine if presented expertise is accurate would be to confirm through follow-up methods such as checking listed references. An example of recent searches of online résumés might find the ambiguously defined term, "leadership" replacing more specific/operationalized words to indicate expertise (e.g., substituting "Leadership" after Business instead of more finite terms, "Management, Administration, or Marketing"). A potential employer may ponder why the finite terminology was not used.

Similar to the false résumé, one might purposefully enable false expertise by hiring an educator with his/her degree from a non-accredited institution. Earlier in this paper, the author discussed the criteria of earning a degree from institutions that have undergone programmatic and institutional reviews. However, there are several institutes operating that claim to offer degrees in particular fields of study (including education 
fields) that have not undergone the review process by expert boards (i.e., accreditation boards) and are frequently referred to as "degree-mills". In the U.S., it has become more common in recent years to find individuals that have had degrees conferred from these schools. While some of these non-accredited schools are now bankrupt or defunct, others continue to operate propagating insincere aspirations for their student body (i.e., earning degrees in $1 / 4$ the time). It is not difficult to imagine how the credibility of the entire education field could be affected by hiring/enabling individuals with non-accredited degrees to act in the same capacity as individuals with degrees from accredited institutions.

Profiteering or Conflicts of Interest (CoI) have become a purposeful interference with expertise. Due to lack of accountability there have been instances reported of $\mathrm{CoI}$ within the education discipline. Principle Investigators may be awarded a grant and yet fail to disclose that they have a percent ownership in the product that they have been asked to investigate. Or, corporations may provide funding to academic researchers to study said company (i.e., British Petroleum provided funding to the University of South Alabama to study the effects of the Gulf Oil Spill caused by their company) [14]. Another example of CoI and Profiteering occurring at the academic education level was Brown University's engagement with the pharmaceutical company SmithKlineBeecham/GlaxoSmithKline to study the effects of the drug, Paxil (study 329) in which the primary investigator had received tens of thousands of dollars from the company and has since been speculated to have been ghostwritten by a public relations firm rather than the academic [15]. Examples, of CoI, like the ones discussed often cause a poor outlook to the academic educator's credibility and reputation to remain unbiased in their freedoms.

Perhaps, the most damaging purposeful enabling of false expertise occurs when society conflates "authority" for "expertise." Consequentially, societal decisions are made by individuals that have authority but possibly not the expertise to warrant an appropriate decision being made. While this can be seen commonly throughout elected positions, it is arguably most damaging when it occurs at appointed levels (i.e., school principals, college provosts, etc.). Authority figures without the necessary expertise can affect the academic educator or grade school educator by making damaging decisions without consultation or regard for the experts in the discipline. For example, the non-expert authority might make a decision that is damaging to one educator while in the best interest of another educator. One specific example occurs when academic administrators attempt to quantify scholarly productivity for academic educators without regard to the quality of the academic scholar's work. In this example one would argue that there exist expertise benefits in pursuing longitudinal research, however, the academic educator would be discouraged from longitudinal research in pursuit of satisfying the quicker quantity criteria enforced by the administration.

\subsection{Accidental}

Not all enabling is purposeful, sometimes, false expertise is accidentally enabled without awareness of the action. For example, it is common in the higher education discipline to arrange search committees to monitor the applications of potential candidates. Naturally, search committee members have other responsibilities to their career aspirations and therefore can forget or accidently neglect following up with all candidates' references. This negligence, while not intentional, could lead to a hire that is not the candidate with the most expertise or a candidate who was not fully vetted.

Socialized dispositions can accidentally enable false expertise. For example, it is a misconception that teachers who have children of their own will be more effective in the classroom [16]. This can frequently be attributed to socialized dispositions even though it ignores that earned expertise in critical parenting skills does not equate to learned expertise in critical teaching skills.

Accidental enabling of false expertise can occur when false assumptions are made by an individual. For example, it is not astonishing to learn that academic educators have made false assumptions which can happen when making the wrong inference from a correlation. It is common lay person language in the U.S., for example, to infer that smoking causes health problems. Sometimes, the lay person will even phrase a definitive conclusive statement to say something similar to, "smoking causes health problems." However, the highest ranking medical office in the U.S. (the Surgeon General's Office), and debatably an office with considerable more expertise than the lay population, has not always made an absolute causal claim [17]. In fact, the Surgeon General's office has historically been careful to indicate that smoking is correlated with high levels of health complications while at the same time cautious to avoid stating conclusive causal relationships because the credibility of the Surgeon General's office would be at risk if future research were to find that a causal conclusion was inaccurate [17]. Another example includes the false correlations that may occur with constant volunteerism. An individual that volunteers for many services might be viewed as an "expert" in the field/discipline that $\mathrm{s} /$ he is volunteering because they are highly visible. In reality, however, the only expertise being garnered by said individual is expertise in "volunteering." A person may, also, make false assumptions due to Attribution theory. Attribution theory claims that one tends to 
attribute their failures and successes to unrelated concepts such as luck (i.e., the baseball player attributes his success not to his skill but rather to the order that he put on his socks). One can see how false assumptions may be made when interpreting correlations as causal. For every causal relationship claim that ends up being incorrect, both credibility and the trust that the public are willing to place in an expert are at risk of being decreased.

Further examples of accidental enabling of false expertise can be due to tradition or culture of fear. Sometimes experts make decisions based on tradition rather than rationale. Perhaps, one makes decisions because it is, "the way things have always been done." Others, might make harmful decisions to the education discipline based on fear. Expert educators may be frightened and discouraged from making a rationale decision due to the "offenses" that they fear may occur. For instance, the academic educator may refrain from speaking about a relevant topic due to the sensitive nature of the content and fear from disciplinary action from the administration for offending the student. Specifically, as an example, it is possible that the Music educator might refrain from lecturing about specific cultural types of music due to the administrations views (and possible threat of disciplinary action) of potential cultural offense to the student. Culture of fear and traditions can effectively silence expertise.

\section{Spotting a False Expert}

Caprino [18] has identified characteristics, in a business setting, that one might look for in an expert. In addition, one might be alerted to the characteristics of a false expert. This author has provided a table and discussion below to help the reader differentiate between some of those characteristics.

Table 2. Identifying an expert

\begin{tabular}{|l|l|}
\hline Experts: & False Experts: \\
\hline $\begin{array}{l}\text { Focus on advancing the } \\
\text { field. }\end{array}$ & $\begin{array}{l}\text { Focus on advancing } \\
\text { themselves within the } \\
\text { field. }\end{array}$ \\
\hline Can say, "I don't know." & $\begin{array}{l}\text { Frequently create or } \\
\text { invent answers to } \\
\text { questions. }\end{array}$ \\
\hline $\begin{array}{l}\text { Demonstrate intellectual } \\
\text { honesty. }\end{array}$ & $\begin{array}{l}\text { Frightened of } \\
\text { contradictory evidence. }\end{array}$ \\
\hline Curious. & Lack of curiosity. \\
\hline Shares knowledge freely. & $\begin{array}{l}\text { Usually wants something } \\
\text { in return for sharing. }\end{array}$ \\
\hline
\end{tabular}

Characteristics identified by Capriano [18] as being shared by experts includes demonstrating intellectual honesty. Experts will be honest in their assessments. Further, experts will be able to say, "I do not know," when they truly do not know an answer to a question.
Experts are curious and will frequently seek to answer the questions they do not know through inquiry and hypothesis testing. Finally, experts are willing to share knowledge freely which helps advance the field.

In contrast, false experts are usually quick to answer questions that they do not know the answer (with confidence) in their oft times incorrect answer. One might have experienced a situation where a false expert "invents" an answer. Even when confidence in the incorrect answer is high, the answer is still incorrect and has been fabricated. The false expert can be identified by a genuine lack of curiosity and are challenged by the introduction of contradictory evidence. The false expert will usually want something in return for sharing their knowledge (i.e., financial incentives) rather than sharing with their colleagues and false experts are focused on advancing themselves rather than the field of study [18].

\section{Summary of Fabricated Expertise Effects on Educators' Freedom}

Throughout history there have been documented cases of expert educators who were persecuted for exercising their freedoms due to the unpopular discourse that they pursued (Socrates, Galileo Galilee, John Scopes, Bruno, etc.). Therefore, in the early $19^{\text {th }}$ century, Lehrfreiheit \& Lehrnfreit [19] argued that the academic educator (as the expert) should be allowed to teach whatever they felt was appropriate and necessary to facilitate learning. Concurrently, they also reasoned that the educator needed freedom to pursue lines of inquiry that best led to their understanding of questions in their discipline/field of study, even if those lines of inquiry were considered by the general public to be restricted. "Argumentum ad Vericundiam," is a Latin phrase that translates to "appeal to authority (even if that authority is false)." "Authority" is not to be conflated with "expertise." "Authority," rather, is the power to make decisions; And, as has been rationalized, not everyone with authority has expertise. Are we as educators expected to appeal to authority, even if that authority has no genuine expertise? Ledoux, Marshall, and McHenry [20] examined the attrition of educators' freedoms when educators allow for authority to make decisions that are not in the best interest of either the discipline or the educator. Unfortunately, enabling of false expertise has led to educators conceding their earned expertise to authority (Argumentum ad Vercundiam). These concessions have caused a loss of trust, faith, and credibility in the education profession [20].

Considering the potential damage that could be inflicted on the education profession due to enabling of false expertise, this author concludes with the following philosophical questions: When we blindly follow authority rather than questioning authority without expertise, what are the potential damages to our 
freedoms? Specifically, this author ponders what may happen to our freedom of inquiry? Most importantly, do we as educators lose the public trust when false expertise has been exposed? And, if we lose our public trust, do we also lose our freedoms? Finally, if we lose our freedoms; What do we have left?

\section{Bibliography.}

[1] Ericsson, K. A. \& Smith, J. (1991). Toward a General Theory of Expertise: Prospects and Limits; Cambridge University Press: Cambridge, EN.

[2] Ericsson, K. A., Prietula, M. J., \& Cokely, E. T. (2007). 'The Making of an Expert', Harvard Business Review; https://hbr.org/2007/07/the-making-of-an-expert (July, 2007).

[3] Ericsson, K. A. (2008). 'Deliberate Practice and Acquisition of Expert Performance: A General Overview', Academic Emergency Medicine 15(11), pp. 988-994.

[4] Lebowitz, S. (2016). 'Anders Ericsson: How to Become an Expert at Anything', Business Insider; https://www.businessinsider.com/anders-ericsson-how-tobecome-an-expert-at-anything-2016-6 (June, 2016).

[5] Berliner, D. C. (1994). 'Expertise: The Wonders of Exemplary Performance', in John N. Mangieri \& Cathy Collins Block (Eds.) Creating Powerful Thinking in Teachers and Students; Holt, Rinehart, and Winston: Fort Worth, TX, pp.141-186.

[6] Berliner, D. C. (1986). 'In Pursuit of the Expert Pedagogue', Educational Researcher 15(7), pp. 5-13.

[7] Eliot, T. S. (n.d.) In Goodreads.com. Retrieved from https://www.goodreads.com/author/quotes/18540.T_S_Eliot.

[8] Firestein, S. (2012). 'Ignorance: How It Drives Science', Oxford University Press: Oxford, EN.

[9] Marion, J. L. (2013). 'The Universality of the University', Communio 40(1); pp. 64-76.

[10] Enable. (n. d.). In Freedictionary.com. Retrieved from https://www.thefreedictionary.com.

[11] Khaleghi, K. (2012). 'Are You Empowering or Enabling', Psychology Today; https://www.psychologytoday.com/us/blog/the-anatomy-ofaddiction/201207/are-you-empowering-or-enabling (July, 2012).

[12] Kominsky, J. F., Langthorne, P., \& Keil, F. C. (2016). 'The Better Part of Not Knowing: Virtuous Ignorance', Developmental Psychology 52(1), pp. 31-45.

[13] Dunning, D., Johnson, K., Ehrlinger, J., \& Kruger, J. (2003). 'Why People Fail to Recognize Their Own Incompetence', Current Directions in Psychological Science 12(3), pp. 83-87.
[14] Lea, R. (2010). 'BP, Corporate R \& D, and the University', American Association of University Professors; https://www.aaup.org/article/bp-corporate-rd-and-university (November/December 2010).

[15] Heck, I. (2014). 'Controversial Paxil Paper Still Under Fire 13 Years Later', The Brown Daily Herald; https://browndailyherald.com/2014/04/02/controversialpaxil-paper-still-under-fire-13-years-later/

[16] Bokas, A. (2016). 'Who is the Expert: Parents or Teachers? Both?', Getting Smart; https://www.gettingsmart.com/2016/03/expert-parentsteachers/ (March, 2016).

[17] Markel, H. (2018). 'This Surgeon General's Famous Report Alerted Americans to the Deadly Dangers of Cigarettes', PBS News Hour; https://pbs.org/newshour/health/this-surgeon-generalsfamous-report-alerted-americans-to-the-deadly-dangers-ofcigarettes (11, January, 2018).

[18] Caprino, K. (2014). 'Are You Dealing With a Real Expert or a Fake? 7 Ways to Tell', Forbes; https://www.forbes.com/sites/kathycaprino/2014/05/19/areyou-dealing-with-a-real-expert-or-a-fake-7-ways-to-tell/amp (19 May 2014)

[19] Commager, H. S. (1963). 'The University and Freedom: Lehrfreiheit \& Lehrnfreiheit', The Journal of Higher Education 34(7), pp. 361-370.

[20] Ledoux, M. W., Marshall, T., \& McHenry, N. (2010). 'The Erosion of Academic Freedom', Educational Horizons 88(4), pp. 249-256. 